\title{
The environmental issue. A challenge for new generation polyolefins*
}

\author{
Ugo Romano ${ }^{1}$ and Fabio Garbassi ${ }^{2}$
}

\author{
${ }^{1}$ EniChem SpA, Research \& Technology, S. Donato Milanese, Italy; ${ }^{2}$ EniChem SpA, \\ Novara Research Center "Istituto Guido Donegani", Novara, Italy
}

Abstract: The recent developments in the field of polyolefin technologies is reviewed in the light of the positive impact that they will have on several aspects of environmental issues.

\section{INTRODUCTION}

The modern approach to environmental issues involves deeply the wide sector of materials. Beside several aspects common to other parts of the chemical industry, such as the use of friendly chemicals, clean and safe processes, and very low or zero emissions, other questions must be taken into consideration. It is in fact highly desirable that the material does not have any negative effect on the environment during its transformation into articles or components, or during service. Finally, it is necessary to avoid similar negative effects at the end of their life (Fig. 1). Among materials, polymers show an increasing importance, testified by the fact that the total production capacity per year increased in the last 30 years from less than 1 million tons to more than 150 million tons. A huge fraction of this amount is constituted by thermoplastic polymers, while the remaining is mainly formed by thermosets and elastomers. Applications of plastics can have a long-life or medium-life character, such as, for instance, in buildings or cars, respectively, but a consistent amount is employed in short-life applications, such as packaging. This circumstance favored, since the beginning of environmental concerns, a positive attitude of industry in searching for correct solutions. Considering the full life of a generic polymer, the plastics industry extended recently its direct responsibility from the steps of polymer production and transformation, through the Responsible Care programs activated in industrial countries, also to the last two steps, for example, service life and end-of-life treatments. This was achieved, and continues to be, by means of a variety of operations derived from a strong $R \& D$ effort, which considered all the above steps [1]. Potentially dangerous monomers and chemicals are substituted with others more friendly; polymerization processes are rendered more and more safe and in many cases can be considered as zero emission processes; polymer processing and manufacturing are addressed toward the decrease of gaseous and liquid emissions and energy savings; lightness and insulation properties of plastics are fully exploited in service, allowing the benefit of energy savings to overwhelm the energy required for fabrication. Finally, depending on their chemistry, plastics benefit from a variety of end-of-life treatments ranging from physical recycling to depolymerization or energy recovery, as sketched in Fig. 2. Apart from landfilling, a destiny unwanted and increasingly unfeasible, the following three options are open:

- $\quad$ Mechanical Recycling (MR): largely practiced for industrial scraps, while municipal wastes need complex separation and washing procedures.

- $\quad$ Feedstock Recycling $(F R)$ : specific for polymeric materials, also in a mixed form, and embracing a number of technologies, at a different development stage: chemical depolymerization, pyrolysis, gasification, hydrogenation.

- $\quad$ Energy Recovery (ER): suitable for mixed/contaminated plastics. The calorific content of plastics is recovered by burning the plastics waste alone or together with fossil fuels.

*Pure Appl. Chem. Vol. 72, No. 7, 2000. A special topic issue on green chemistry. 


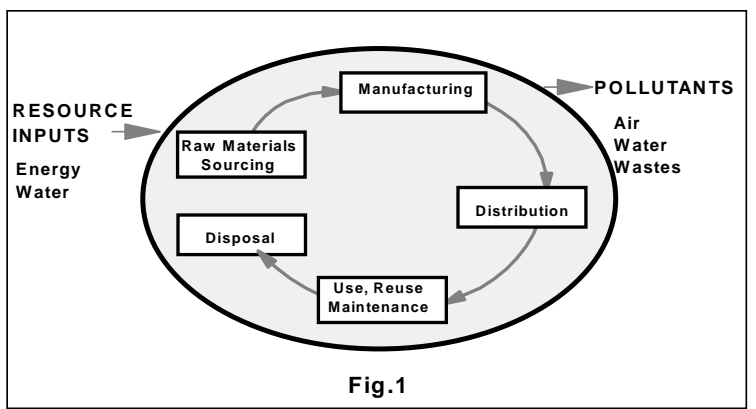

Fig. 1 The plastics product life cycle inventory.

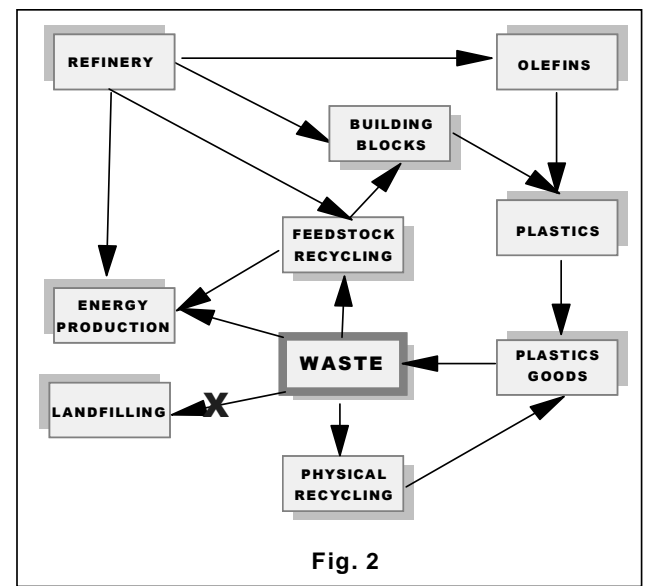

Fig. 2 Simplified sketch of plastics recycling options.

The described options show different efficiency grades as reported in Table 1 [2]. The general attitude is that the best solution for such a problem can be reached through a multiple approach, adapted to the specific characteristic of waste.

Table 1 Energy savings of several recycling options in comparison to landfill.

\begin{tabular}{lc}
\hline Recycling option & Energy saving $(\mathrm{MJ} / \mathrm{kg})$ \\
\hline Mechanical (bottles) & 38.4 \\
Mechanical (films) & 30.0 \\
Syngas & 10.0 \\
Hydrogenation & 23.8 \\
Thermolysis & 29.3 \\
Monocombustion & 26.4 \\
Municipal waste incineration & 15.9 \\
\hline
\end{tabular}

\section{THE ASTONISHING VITALITY OF POLYOLEFINS}

Polyolefins, intended as polymers and copolymers of ethylene and propylene, represent more than $40 \%$ of plastics produced every year, with a clear tendency to increase such a percentage. Conventionally, polyolefins include three polyethylene-based materials, that is, high density (HDPE), low density (LDPE) and linear low density (LLDPE), polypropylene (PP) and ethylene-propylene-(diene) copolymers and terpolymers (EP(D)M elastomers). Thus, polyolefins play a major role in the environmental issue, and every progress obtained for them is a substantial progress for the whole issue. Furthermore, polyolefins take great advantage of their chemical nature, being composed by carbon and hydrogen only, with respect to other plastics, like poly(vinyl chloride) (PVC), polyamides, and polyurethanes.

The industrial history of polyolefins began in 1937, when ICI patented the LDPE production with the high-pressure radical process. Since then, continuous progress occurred both on the process and products side, resulting in the so-called advanced $\mathrm{ZN}$ technologies. They include multireactor processes, broad molecular weight distribution (MWD), bimodal MW, and super-hexene technologies [3]. 


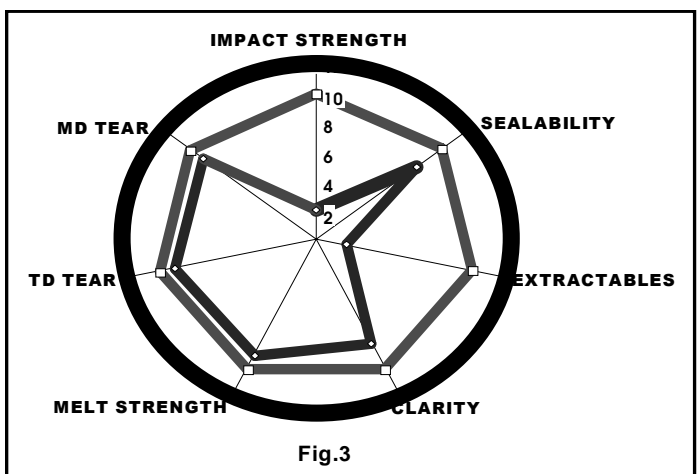

Fig. 3 Properties of PE from new technologies (external star) with respect to traditional products (internal star).

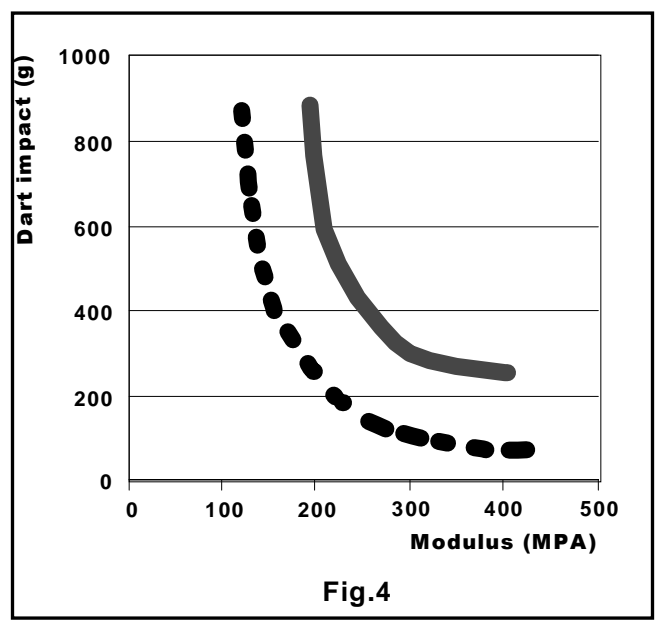

Fig. 4 Dart impact vs. modulus for metallocene LLDPE (continuous line) and traditional LLDPE (dotted line).

In the early 90s, a new catalyst family based on metallocene compounds [4] caught up at the industrial level with the more consolidated ZN catalysts. New opportunities were opened mainly from the point of view of products, and consequently also applications. This development was rapidly followed by the discovery of new single-site catalysts based on ligands different from metallocenes and unconventional transition metals. Even if the latter are yet in the laboratory or development stage, they seem to offer new perspectives for making tailored materials, like olefin-polar monomer copolymers or hyperbranched polyethylenes [5].

Today, polyolefins are industrially produced with four basic processes, that is, high pressure, slurry, solution, and gas-phase. Modern technologies include also hybrid multireactor processes. Starting from the mid 1990s, metallocene-based catalysts were used to produce polyolefins industrially, reaching in 1999 the amounts of 945000 tons of PE and 85000 tons of PP, respectively [6].

With respect to heterogeneous $\mathrm{ZN}$ catalysts, metallocenes are able to produce resins with specific characteristics, such as narrower MWD, more uniform distribution of comonomers along the polymer chain, wider amount of copolymers introduced, or a remarkably better control of long-chain branching [7]. In addition, tacticity of polymers is strictly correlated (in the case of PP) to the metallocene catalyst symmetry [8]. The resin characteristics have a strong influence on many applicative properties, such as clarity, gloss, impact resistance, heat seal properties, breathability, etc. The final result was a great extension of properties and application ranges, as exemplified in Fig. 3. The novelty is that such improvements were not achieved to the detriment of other properties. In fact, the performance curve for LLDPE (Fig. 4) shows a remarkable shift of properties towards higher values for a metallocene-derived material with respect to a traditional one [9].

\section{INFLUENCE OF NEW POLYOLEFINS ONTHE ENVIRONMENTAL ISSUE}

The above-described advancements in polyolefin production had several beneficial influences on the environmental issue. Such a result was caused by a variety of elements, described in the following with several meaningful examples.

- $\quad$ Yield increase. The increase of catalytic activity for the polymerization of PP was spectacular. Five generations of catalysts based on $\mathrm{TiCl}_{3}$ or $\mathrm{TiCl}_{4}$ with other components allowed an increase

(C) 2000 IUPAC, Pure and Applied Chemistry 72, 1383-1388 
in the productivity of two orders of magnitude (Fig. 5), improving at the same time the control of stereospecificity [10]. These improvements allowed a great simplification of processes, and consequently of industrial plants, because many plant sections, such as catalysts residue removal, separation of the amorphous fraction, extrusion of the polymer, and effluents treatment, were no longer required [11].

- $\quad$ Process advancements. Gas-phase processes for PE and PP had great success in reducing waste production and energy consumption. The most applied process for LLDPE, (Unipol of Union Carbide), based on a single fluidized-bed reactor, achieved an energy saving estimated in the range $12-16 \mathrm{MJ} / \mathrm{kg}$ PE by means of the injection of liquid monomer feed and recycle into the reaction zone, so removing the heat of reaction by heat of evaporation. This "condensing mode" was estimated to increase the space-time yield for polymerization up to 60\% [12]. The Spheripol process of Montell operates with multireactor plant configurations, constituted by a pair of loop reactors followed by a gas-phase polymerization reactor, so that the production of wastewater and solid waste passed from $1.5-2 \mathrm{~m}^{3} / \mathrm{t}$ and $80 \mathrm{~kg} / \mathrm{t}$ respectively to 0 . In the meantime, the electric power and steam consumption were cut by $80 \%$ and $90 \%$, respectively [13]. A further development has been recently announced, and consists of a new reactor design, able to produce PE- or PP-based materials and alloys with enhanced properties. This new technology, named MultiZone Circulating Reactor (MZCR) is based on circulating continuously a growing polymer granule between two interrelated reactor zones, operating at rather different conditions [14].

- $\quad$ Property improvements. Property improvements resulting from the new technologies allow also a remarkable downgauging of products. The HDPE produced with the Borstar process (Borealis), which combines a slurry loop reactor with a gas-phase reactor, allows a decrease in wall thickness of $400-\mathrm{mm}$ tubes from 36.3 to $26.9 \mathrm{~mm}$, due to the improved mechanical strength of the bimodal resin produced. As a consequence, a saving of 33\% of material is obtained [15].

- Widening of the application range. With their ability to control the molecular structure of polyolefins, the new technologies widely expanded the number of grades potentially obtainable in plants. This is particularly evident in the case of PE-based materials, where the new technologies demonstrated an ability to cover the entire range of attainable densities, filling in particular the gap between LLDPE (lower density $0.915 \mathrm{~g} / \mathrm{cm}^{3}$ ) and EPR elastomers (density range 0.86$0.88 \mathrm{~g} / \mathrm{cm}^{3}$ ). The ability to synthesize materials with similar chemical composition, but having a large spectrum of properties, opened the possibility to use, in complex systems, different materials of the same chemical nature, as in the case of car dashboards, where different PP-based materials of very different rigidity can be suitably combined. The new properties can also favor the substitution of less-friendly materials. LLDPE grades obtained with a metallocene catalyst showed the capability to recover fully and rapidly a $150 \%$ film extension [16], becoming able to substitute PVC in some relevant packaging applications. Polyolefin-based foams are currently competing with expanded polyurethane foams in the automotive sector. Also traditional engineering polymers are affected by this interpolymer competition. In Table 2, some properties of Hivalloy resins

Table 2 Properties of $30 \%$ glass fiber thermoplastic composites.

\begin{tabular}{lccc}
\hline Matrix & $\begin{array}{c}\text { Notched Izod } \\
\left(\mathrm{kJ} / \mathrm{m}^{2}\right)\end{array}$ & $\begin{array}{c}\text { Flex. strength } \\
(\mathrm{MPa})\end{array}$ & $\begin{array}{c}\text { Flex. modulus } \\
(\mathrm{MPa})\end{array}$ \\
\hline Nylon 6 (dry) & 11 & 190 & 7600 \\
PBT & 8 & 190 & 8300 \\
Hivalloy & 12 & 180 & 7600 \\
conventional PP & 8 & 140 & 5700 \\
\hline
\end{tabular}

(C) 2000 IUPAC, Pure and Applied Chemistry 72, 1383-1388 


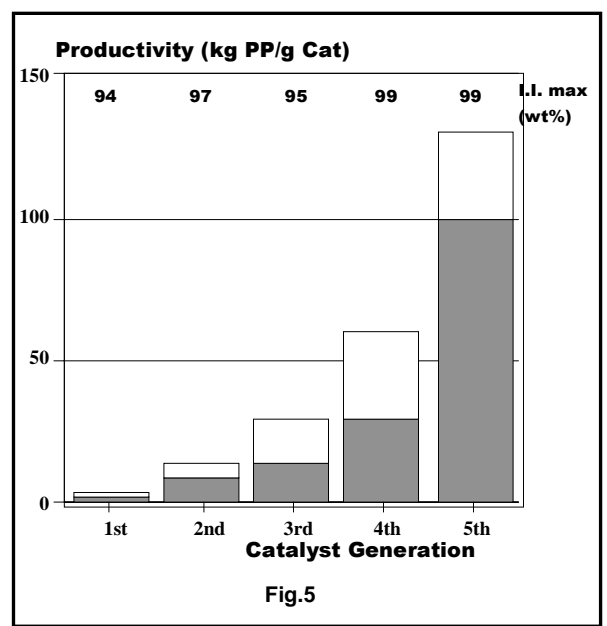

Fig. 5 Increase of productivity of ZN catalysts in the polymerization of propylene. White areas represent variability. Top numbers over the bars

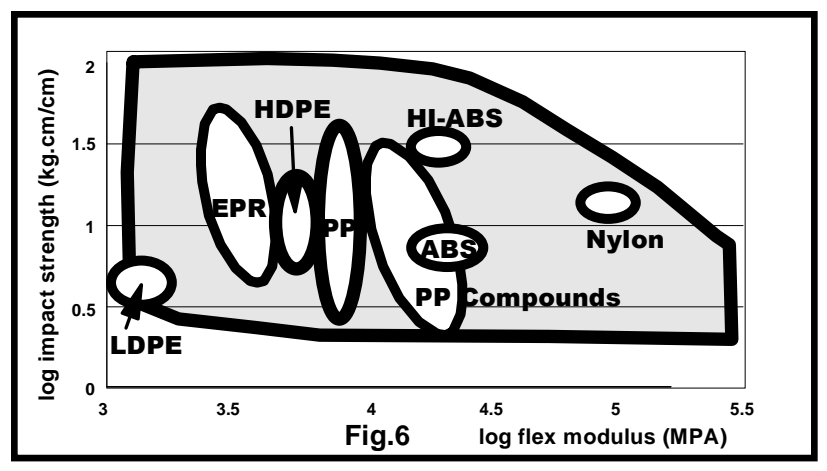

Fig. 6 Performance field of new technology polyolefins (gray area) with respect to other materials (white areas).

obtained with a Montell multireactor technology and reinforced with $30 \%$ of glass fibers are compared with those of the corresponding materials having different matrices. It is apparent that impact and strength properties are remarkably improved with respect of conventional PP, reaching values similar to those of PBT and nylon 6 [17].

It has been estimated that about two-thirds of the substitution market growth of PP in the 1989-1996 period concerned less environmentally friendly materials such as polyamides, PVC, $\mathrm{ABS}$, and polystyrene. In perspective, the new technologies began to cover a broad range of property combinations, reserved up to now to many different materials (Fig. 6).

- New Materials. With respect to this compilation, it is necessary to remark that the new technologies developed in the polyolefin field demonstrated also an ability to synthesize new materials. This is true on one hand for the Reactor Granule Technology, able to produce in situ polyolefin alloys [9], and, on the other hand, to metallocene catalysts, suitable for the synthesis of syndiotactic polystyrene [18], syndiotactic polypropylene [8], elastomeric homopolymer PP [19], cyclo-olefin copolymers (COCs) [20], and ethylene-styrene copolymers [21].

\section{CONCLUSIONS}

Polyolefins are winning the interpolymer/intermaterial competition in many market sectors, due to the technical results and price reductions achieved by a series of new production technologies. Materials made in these ways will displace some relevant fraction not only of the corresponding polymers made with traditional processes (i.e., LDPE, LLDPE, HDPE, PP, and EPDM), but also materials with a different chemical structure, such as PVC, EVA, ABS, and low-performance engineering plastics. This development will have beneficial effects on the environmental issues for several reasons, such as the friendly chemical nature of such materials, the availability of a wide range of recycle/recovery solutions, accompanied by remarkable simplification elements on them, and finally on energy and materials savings due to the efficiency reached by the production processes. 


\section{ENICHEM'S ENGAGEMENT IN GREEN CHEMISTRY}

The EniChem R\&D structures are currently engaged in several green chemistry research programs. Studies are active for the substitution of dangerous chemicals like phosgene in the synthesis of important building blocks like dimethyl carbonate and its derivatives (usable also as solvents with low environment impact), and for the use of hydrogen peroxide in the synthesis of propylene oxide and caprolactam using zeolite-based catalysts. Also, some relevant recycling and environmental studies are carried out, in the framework of international collaborative projects. Among them Recycling of Car Plastics (RECAP),

Remediation of Polluted Industrial Sites (REPIS) and Protection of Groundwater Resources (PURE) can be cited.

\section{REFERENCES}

1. Workshop Report, The Role of Polymer Research in Green Chemistry and Engineering, University of Massachussets, NETI (1998).

2. J. Brandrup. Macromol. Symp. 144, 439 (1999).

3. D. F. Bari. In Metallocene-Catalyzed Polymers, G. M. Benedikt and B. L. Goodall (Eds.), p. 351, Plastics Design Library, Norwich (1998).

4. H. Sinn and V. Kaminsky. Adv. Organomet. Chem. 18, 99 (1980).

5. L. K. Johnson, C. M. Killian, M. Brookhart. J. Am. Chem. Soc. 117, 6414 (1995).

6. Chem. Week, Feb. 9, 2000, p. 36.

7. K. B. Sinclair. In Metallocene-Catalyzed Polymers, G. M. Benedikt and B. L. Goodall (Eds.), p. 63, Plastics Design Library, Norwich (1998).

8. E. S. Shamshoum and D. Rauscher. In Metallocene-Catalyzed Polymers, G. M. Benedikt and B. L. Goodall (Eds.), p. 21, Plastics Design Library, Norwich (1998).

9. K.W. Swogger. In Metallocene Technology, G. M. Benedikt. (Ed.), p. 283, Plastics Design Library, Norwich (1999).

10. E. Albizzati and M. Galimberti. Chim. Ind. 79, 1053 (1997).

11. P. Locatelli. TRIP 2, 87 (1994).

12. F. J. Karol. In Metallocene-Catalyzed Polymers, G. M. Benedikt and B. L. Goodall (Eds.), p. 35, Plastics Design Library, Norwich (1998)

13. T. Simonazzi and U. Giannini. Gazz. Chim. Ital. 124, 533 (1994).

14. Europ. Chem. News 21-27 Feb. 2000, p.28.

15. Borealis A/S Information Sheet IN0084/GB (1998).

16. A. A. Montagna. CHEMTECH Oct. 1995, p. 44.

17. P. Galli, J. C. Haylock, E. Albizzati, A. DeNicola. Macromol. Symp. 98, 1309 (1995).

18. N. Ishihara, N. Kuramoto, M. Uoi. Macromol. 21, 3356 (1988).

19. C. W. Coates and R. W. Waymouth. Science 267, 217 (1995).

20. C. Lee and B. B. Singh. New Generat. Polyol. 2, 2 (1996).

21. J. C. Stevens. Proc. MetCon '93, p. 157, Houston (1993). 